\title{
Incidence of preterm births admissions in Uganda, 2015-2019
}

\author{
Job Morukileng ( $\sim$ jmorukileng@musph.ac.ug) \\ Uganda Public Health Fellowship Program \\ Wilberforce Mugwanya \\ Ministry of Health \\ Robert Mutumba \\ Ministry of Health \\ Maureen Katusiime \\ Uganda Public Health Fellowship Program \\ Aggrey Byaruhanga \\ Uganda Public Health Fellowship Program \\ Doreen N. Gonahasa \\ Uganda Public Health Fellowship Program \\ Bob Omoda Amodan \\ Uganda Public Health Fellowship Program \\ Steven Kabwama \\ Uganda Public Health Fellowship Program \\ Daniel Kadobera \\ Uganda Public Health Fellowship Program \\ Lilian Bulage \\ Uganda Public Health Fellowship Program \\ Alex Riolexus Ario \\ Uganda Public Health Fellowship Program
}

\section{Research Article}

Keywords: Preterm, admissions, increasing incidence, live births, Uganda

Posted Date: February 8th, 2022

DOI: https://doi.org/10.21203/rs.3.rs-1263340/v1

License: () (7) This work is licensed under a Creative Commons Attribution 4.0 International License. Read Full License 


\section{Abstract}

Background: Complications of preterm births are the largest cause of neonatal deaths and the second leading cause of deaths among children $<5$ years globally. The preterm birth rate in Uganda is estimated at 6.6\%. Reduction of this rate is needed to achieve the United Nations Sustainable Development Goal to end all preventable deaths among newborns and children aged $<5$ years by 2030 . We describe the trends and distribution of preterm births admissions in Uganda during 2015-2019 for advocacy, planning, and targeted interventions.

Methods: We used national preterm birth admissions data from 2015-2019 abstracted from the District Health Information System 2 (DHIS2) to calculate national, regional and district annual incidence of preterm births admissions. DHIS2 defines preterm birth as birth occurring <37 weeks of gestation. We used preterm birth admissions as numerator and the total livebirths (LB) as the denominator. We used line graphs to demonstrate the trend of annual incidence for the national and regional levels and choropleth maps to show district level distribution. Significance of the trend of annual incidence was tested using modified Poisson regression with unbiased sandwich standard errors, considering calendar year as independent and preterm births admissions as dependent variable

Results: The national annual incidence of preterm birth admissions/1,000 LB has significantly increased from 3 in 2015 to 14 in 2019 (Incidence Risk Ratio $(\mathrm{IRR})=1.3, p=0.003$ ). The annual incidence of preterm birth admissions/1,000 LB increased significantly in three regions of Uganda during 2015 -2019 (Central Region from 3 to 21, IRR=1.5, $p<0.0001$; Western Region from 4 to 15 IRR=1.2, $p=0.039$; Northern Region from 3 to 10, IRR=1.2, $p=0.008$; Eastern Region from 2 to 8 , IRR=1.3, $p=0.086$ ). The Choropleth map showed minimal clustering of high incidence of preterm birth admissions at district level.

Conclusion: Incidence of preterm birth admissions increased nationally and regionally in Uganda from 2015-2019. There is need to plan for and prepare health facilities to manage preterm labor and preterm babies, as well as identifying reasons for the increase. Equipping health facilities and training health workers to manage preterm labor and babies should be prioritized.

\section{Background}

Preterm birth is a growing concern globally(1), with many countries reporting an increasing trend (2-5). Preterm birth is of paramount significance for achieving United Nations Sustainable Development Goal 3 target 3.2, which aims to end all preventable deaths of newborns and children aged $<5$ years by 2030. Complications of preterm births are the largest cause of neonatal deaths and the second leading cause of deaths among children $<5$ years globally(6). Preterm Birth is birth that occurs before 37 weeks of pregnancy, sub-categorized

as extremely preterm ( $<28$ weeks), very preterm ( 28 to $<32$ weeks), and moderate to late preterm ( 32 to <37 weeks) $(6)$. Every year, an estimated 15 million babies are born too early, with approximately 1 million of those children under 5 years of age dying due to complications of preterm birth globally (7).

Whereas $60-85 \%$ of preterm births occur in Africa and South Asia $(6,8)$, preterm birth is a global problem. The global preterm birth rate increased from $9.8 \%$ in 2000 to $10.6 \%$ in 2014. During the same period, an estimated $6.6 \%$ of births were preterm in Uganda (9). In lower-income countries (LICs), $12 \%$ of babies are born too early compared with $9 \%$ in higher-income countries (HICs). Disparities exist in survival rates of preterm babies around the world(6). Although the causes of preterm birth are unknown in about $50 \%$ of the cases, preterm birth can be caused by fetal or maternal factors such as having a previous premature birth, multiple pregnancy, drug use, stress, infections and chronic conditions such as diabetes and high blood pressure $(6,10,11)$.

Preterm babies are prone to serious illness or death during the neonatal period. Those who survive are at increased risk of lifelong disability and poor quality of life (12-16). Complications of prematurity such as immature lungs, difficulty regulating body temperature, infections, poor feeding and slow weight gain (17), are the single largest cause of neonatal death and the second leading cause of deaths among children under the age of 5 years (12, 18). In Uganda Preterm births are directly responsible for $8 / 27$ neonatal deaths per 1,000 live births (19) and remains among the top three causes of neonatal mortality (20).

If Uganda is to accelerate reduction in neonatal mortality, current local data are crucial to inform priorities and drive advocacy to scale-up effective interventions to avert preterm births. However, there is paucity of local data on the current trends of premature birth and its distribution in Uganda. We described the trends and distribution of preterm births in Uganda between 2015-2019 to support advocacy, planning, and targeted interventions.

\section{Methods Study setting}

Uganda has an estimated population size of 34.6 million people. There are four regions in Uganda, each region is partitioned into districts making a total of 135 districts (21). The Uganda health system faces challenges in providing care to high risk newborn babies such as preterm babies. The 2013 national service availability and readiness assessment indicated that only $14 \%$ of facilities in Uganda were adequately stocked with corticosteroids for management of preterm labour, $69 \%$ had adequate antibiotics for managing infections (common in preterm babies) and only $9 \%$ had new-born resuscitation equipment (22). Additionally, the neonatal referral facilities in Uganda have challenges in meeting the basic requirements for facility readiness to manage the increasing number of high risk newborns like preterm babies (23).

\section{Study design and data source}

This was a descriptive analysis of secondary data on preterm birth among newborns (birth before 37 weeks of gestation) between 2015 to 2019 from the Uganda District Health Information System (DHIS-2). DHIS-2 is a web-based reporting tool introduced to Uganda in 2012, with full roll-out across the country in 
2013 (24). It is a tool for collection, validation, analysis, and presentation of aggregate and patient based statistical data, tailored (but not limited) to integrated health information management activities (25).

The preterm birth data are routinely generated at health facilities using the integrated maternity register, under variable 9 . In the old version of the maternity register, variable 9 had two columns, the first captured the weeks of gestation while the second column captured births categorized as "Term (T)" if it occurred at $\geq 37$ weeks or "preterm $(P)$ " if $<37$ weeks, based on the weeks of gestation. Preterm babies that need admission for management are recorded in the newborn inpatient register (variable 17 "Term/Preterm"). The data from these registers are aggregated into a health facility monthly report (paper form) which is initially submitted to health sub-district, then to the district health offices. At district health office, the data from the paper-based reports are entered into DHIS-2. DHIS-2 groups the data into multiple data elements at national, regional, district, subcounty and facility levels.

\section{Study variables and data analysis}

We abstracted data for preterm admissions from the DHIS-2 data elements denoted "108-6 Premature baby as condition that requires management." and Live births data from "105-2.2d Deliveries in unit.". We disaggregated the data into national, regional, and district levels.

We calculated the annual incidence rates for preterm births admissions for each level (national, regional, and district level), by dividing the total preterm births admitted during the year by the total live births that year and multiplying by 1,000 . We obtained the mean annual incidence rates for the national and regional levels by adding annual incidence rates for the five years of study and dividing by five. The reporting rates for preterm births admissions over the five years was calculated at district level by dividing the number of districts that reported preterm births data in the year by the total number of the districts in the country.

We drew line graphs by plotting annual incidence of preterm births to show the trend of incidence rates for national and regional levels and used choropleth maps (generated using district specific annual incidences of preterm births in Quantum Geographic Information System (QGIS)) to present the distribution of the preterm births admissions across the country. We tested the significance of the trends of preterm births admissions at national and regional levels over the five years of study using generalized linear models of Poisson family with unbiased sandwich standard errors, considering calendar year as independent and preterm births as dependent variable as applied by previous studies(26)

\section{Results}

\section{Trend of annual incidence rate of preterm births admissions at national level, Uganda, 2015-2019.}

At national level, the annual incidence rate of preterm birth admissions significantly increased from 2015 to 2019 (IRR=1.3, $p=0.003)$ (Figure 1). The incidence rate increased by an annual average of $9 / 1,000$ LB. The reporting rate was relatively the same over the years.

\section{Trend of annual incidence rate of preterm births admissions, regional level, Uganda, 2015- 2019}

Consistent with the national trend, we observed a statistically significant increase in the incidence rates of preterm birth admissions/1000 LB/year in three regions of Uganda, with eastern region being the only region to register a declining incidence between 2018 and 2019 thus a non-significant increase over the five years (Table 1). Central region registered the highest mean annual incidence rate of 12 preterm birth admissions/1000 LB over the 5 years, while eastern and northern regions registered the lowest mean incidence rate of 7 preterm birth admissions/1000 LB in the five years (Figure 2). The reporting rate was relatively the same over the 5 years

Table 1

Significance of the trends of incidence of preterm births admissions at regional level, Uganda, 2015-2019

\begin{tabular}{|lccl|}
\hline Region & IRR & $\mathbf{9 5 \%} \mathbf{C l}$ & P-Value \\
\hline Central Region 2015/2019 & 1.5 & $1.3-1.7$ & $<0.0001$ \\
\hline Eastern Region 2015/2019 & 1.3 & $1.0-1.7$ & 0.086 \\
\hline Northern Region 2015/2019 & 1.2 & $1.1-1.5$ & 0.008 \\
\hline Western region 2015/2019 & 1.2 & $1.1-1.5$ & 0.039 \\
\hline Note: IRR= Incidence Risk Ratio, Cl= Confidence Incidence \\
\hline
\end{tabular}

\section{Spatial distribution of preterm births admission incidence rates, district level, Uganda, 2015-2019}


The geographic distribution of preterm birth admissions/1000 LB in Uganda indicates minimal clustering of high burdened districts in some regions. Nevertheless, we observe more of the districts with $>30$ preterm birth admissions/1000 LB/year in the western and central regions. The years with the highest burden were 2017, 2018, and 2019 (Figure 3).

\section{Discussion}

Our study findings show a significant and steadily increasing trend of preterm birth admissions from 2015 and 2019 across national and regional levels. Our results also indicated a countrywide spatial distribution of incidence of preterm birth admissions at district level. Districts with incidence of $\geq 30 / 1000$ LB was observed in all the four regions of Uganda.

The increasing incidence of preterm birth admissions is consistent with the findings in over 60 countries globally with reliable trends that have shown an increasing rate over the past two decades $(6,7)$. Studies in Uganda and elsewhere have associated the increase to twin pregnancies, nutritional status of the mother (27), history of abortion (28), an increased use of fertility drugs, previous preterm birth, and several other factors $(6,10,11,29)$. In addition, methodological challenges exist in Uganda and other LICs where ultrasound is rarely used in early pregnancy to estimate gestational age. Use of ultrasound (obstetric method) is considered a gold standard for estimation of gestational age (30). However, a less accurate method such as the last menstrual period is often used in Uganda to estimate gestational age. This method may be incorrect with an error margin of up-to 4 weeks. Consequently, more births are classified as preterm than the obstetric method (31). Regardless of the reasons for the increasing trend, managing preterm newborns requires well-equipped health facilities and skilled health personnel as such, the Ministry of Health $(\mathrm{MoH})$ and health implementing partners needs to do an assessment of the current level of preparedness of the health system to manage increasing preterm births.

Our results show that preterm birth is generally distributed all over the country with minor variations across regions. This result may be explained by the fact that the causes of preterm birth are multifaceted and that about $50 \%$ of the preterm birth occur with no known exposures (6). As such, the preterm birth can occur to anyone-anywhere-anytime. This finding suggests need to deliberately plan a countrywide programme that will equip and skill all regional referral hospitals to effectively manage preterm births. Beyond equipment and skills, the health facilities will require neonatal intensive care units (NICU) for specialised care. The $\mathrm{MoH}$ and health implementing partners need to continuously monitor and forecast future trends of preterm births to aid planning for space, equipment, and capacity building.

The study depended on secondary data as such, the analysis was limited to available data variables which may not allow for detailed exploration of the problem. Further studies requiring primary data will need to be conducted for in-depth understanding of the problem.

\section{Abbreviations}

Cl: Confidence Interval

DHIS-2: District Health Information System-version 2

HIC: High Income Countries

IPD: Inpatients' Department

LB: Live births

LIC: Low Income Country

MoH: Ministry of Health

OPD: Out Patients' Department

OR: Odds Ratio

QGIS:Quantum Geographic Information System

WHO: World Health Organization

\section{Declarations}

\section{Ethical approval and consent to participate}

Our study was not submitted to the Institutional Ethics Committee/Institutional Review Board (IRB) for approval, The Office of the Associate Director for Science, U.S. Centers for Disease Control and Prevention determined that this study was not a human subjects research with the primary intent of improving use of data to guide public health planning and practice. All methods in this study were performed in accordance with the relevant guidelines and regulations (e.g. Declaration of Helsinki). Our study utilized routinely generated data in reproductive and infant health department of the Ministry of Health (MoH) stored in the DHIS-2. The DHIS-2 data is aggregate and does not contain personal identifiers. As employees of the reproductive and infant health department of the Ministry of Health and as primary users of the data, administrative permission to access the raw data was not required. We stored the abstracted data set in a password protected computer and only shared it with the investigation team. 


\section{Consent for publication}

Not applicable.

\section{Availability of data and materials}

The datasets used and analyzed during this study belong to the Uganda $\mathrm{MoH}$ and are not publicly available. However, with justified reasons, permission, and access credentials to the DHIS-2 can be obtained from the MoH Uganda.

\section{Competing interests}

The authors declare that they have no competing interests.

\section{Funding and disclaimer}

This project utilized existing data and did not require dedicated funds. However, the lead investigator and several other authors (as per the authorship list) are facilitated by the President's Emergency Plan for AIDS Relief (PEPFAR) through the US Centers for Disease Control and Prevention Cooperative Agreement number GH001353-01 through Makerere University School of Public Health to the Uganda Public Health Fellowship Program, Ministry of Health. Its contents are solely the responsibility of the authors and do not necessarily represent the official views of the US Centers for Disease Control and Prevention/the Agency for Toxic Substances and Disease Registry, the Department of Health and Human Services, Makerere University School of Public Health, or the Ministry of Health.

\section{Authors' contributions}

JM, WM, RM, MK, were involved in the design and implementation of the investigation. AB, and DNG were involved in the data analysis. DK, LB, ARA had primary responsibility for final content. All authors participated in the writing, reading, and approving the final manuscript.

\section{Acknowledgements}

We would like to thank the Ministry of Health for the permission to access the data. We thank the US-CDC for supporting the Uganda Public Health Fellowship Program (UPHFP) activities. Finally, we thank the UPHFP secretariat for the technical support from the inception of the study to final product.

\section{References}

1. World Health Organization. Born too soon: the global action report on preterm birth. 2012.

2. Martin JA, Hamilton BE, Sutton PD, Ventura SJ, Menacker F, Kirmeyer S, et al. Births: final data for 2005. National vital statistics reports. 2007;56(6):1-103.

3. Keirse MJ, Hanssens M, Devlieger H. Trends in preterm births in Flanders, Belgium, from 1991 to 2002. Paediatric and perinatal epidemiology. 2009;23(6):522-32.

4. Langhoff-Roos J, Kesmodel U, Jacobsson B, Rasmussen S, Vogel I. Spontaneous preterm delivery in primiparous women at low risk in Denmark: population based study. Bmj. 2006;332(7547):937-9.

5. Auger N, Gamache P, Adam-Smith J, Harper S. Relative and absolute disparities in preterm birth related to neighborhood education. Annals of epidemiology. 2011;21(7):481-8.

6. Born too soon. The global action report on preterm birth. Geneva: World Health Organization. 2012.

7. Blencowe H, Cousens S, Oestergaard MZ, Chou D, Moller A-B, Narwal R, et al. National, regional, and worldwide estimates of preterm birth rates in the year 2010 with time trends since 1990 for selected countries: a systematic analysis and implications. The lancet. 2012;379(9832):2162-72.

8. Beck S, Wojdyla D, Say L, Betran AP, Merialdi M, Requejo JH, et al. The worldwide incidence of preterm birth: a systematic review of maternal mortality and morbidity. Bulletin of the World Health Organization. 2010;88:31-8.

9. Chawanpaiboon S, Vogel JP, Moller A-B, Lumbiganon P, Petzold M, Hogan D, et al. Global, regional, and national estimates of levels of preterm birth in 2014: a systematic review and modelling analysis. The Lancet Global Health. 2019;7(1):e37-e46.

10. About Kids Health. Preterm Babies. ND. https://www.aboutkidshealth.ca/Article?contentid=1758\&language=English. Accessed on 30 September 2020.

11. Uganda Bureau of Statistics (UBOS) and ICF. Uganda Demographic and Health Survey 2016. Kampala, Uganda and Rockville, Maryland, USA: UBOS and ICF. 2018.

12. World Health Organization. WHO recommendations on interventions to improve preterm birth outcomes. 2015.

13. Himmelmann K, Uvebrant P. The panorama of cerebral palsy in Sweden. XI. Changing patterns in the birth-year period 2003-2006. Acta paediatrica. 2014;103(6):618-24.

14. Moster D, Lie RT, Markestad T. Long-term medical and social consequences of preterm birth. New England Journal of Medicine. 2008;359(3):262-73.

15. Hassell J, Tann C, Idro R, Robertson NJ. Contribution of perinatal conditions to cerebral palsy in Uganda. The Lancet Global Health. 2018;6(3):e248-e9.

Page 5/8 
16. Kakooza-Mwesige A, Forssberg H, Eliasson A-C, Tumwine JK. Cerebral palsy in children in Kampala, Uganda: clinical subtypes, motor function and comorbidities. BMC research notes. 2015;8(1):166.

17. Ministry of Health. Reproductive Maternal, Newborn and Child Health Sharpened Plan for Uganda. 2013. http://speed.musph.ac.ug/wpcontent/uploads/2015/05/Committing-to-Maternal-and-Child-Survival_A-Promise-Renewed.pdf. Accessed 30 September 2020.

18. Liu L, Johnson HL, Cousens S, Perin J, Scott S, Lawn JE, et al. Global, regional, and national causes of child mortality: an updated systematic analysis for 2010 with time trends since 2000. The Lancet. 2012;379(9832):2151-61.

19. Ministry of Health. Situation analysis of newborn health in Uganda: current status and opportunities to improve care and survival. Kampala: Government of Uganda. Save the Children, UNICEF, WHO; 2008. https://www.healthynewbornnetwork.org/hnn-content/uploads/Situation-Analysis-of-Newborn-healthin-Uganda.pdf. Accessed 1 October 2020.

20. Kananura RM, Tetui M, Mutebi A, Bua JN, Waiswa P, Kiwanuka SN, et al. The neonatal mortality and its determinants in rural communities of Eastern Uganda. Reproductive health. 2016;13(1):13.

21. Uganda Bureau of Statistics. Statistical Abstract, accesed on 6 June 2021, available; https://www.google.com/url? $\mathrm{sa}=\mathrm{t} \& \mathrm{rct}=\mathrm{j} \& \mathrm{q}=\&$ esrc=s\&source=web\&cd=\&cad=rja\&uact=8\&ved=2ahUKEwjB0Zve65vyAhUPA2MBHaK0Cm4QFnoECA4QAQ\&url=http\%3A\%2F\%2Flibrary .h $\epsilon$ ByNv. 2020.

22. Ministry of Health. Uganda Services Availability and Readiness Assessment. 2013. http://library.health.go.ug/download/file/fid/2527. Accessed 2 August 2021.

23. Narayanan I, Nsungwa-Sabiti J, Lusyati S, Rohsiswatmo R, Thomas N, Kamalarathnam CN, et al. Facility readiness in low and middle-income countries to address care of high risk/ small and sick newborns. Maternal Health, Neonatology and Perinatology. 2019;5(1):10.

24. Kiberu VM, Matovu JK, Makumbi F, Kyozira C, Mukooyo E, Wanyenze RK. Strengthening district-based health reporting through the district health management information software system: the Ugandan experience. BMC medical informatics and decision making. 2014;14(1):1-9.

25. Kigozi SP, Kigozi RN, Sebuguzi CM, Cano J, Rutazaana D, Opigo J, et al. Spatial-temporal patterns of malaria incidence in Uganda using HMIS data from 2015 to 2019. BMC public health. 2020;20(1):1-14.

26. Atuheire EB, Opio DN, Kadobera D, Ario AR, Matovu JK, Harris J, et al. Spatial and temporal trends of cesarean deliveries in Uganda: 2012-2016. BMC pregnancy and childbirth. 2019;19(1):1-8.

27. Adongo PR. Factors associated with preterm birth among postnatal mothers at Soroti regional referral hospital, eastern Uganda: Busitema; 2019.

28. Owuor RA, Ngerecia J, Mogambi L, Onwong'a I, Seroney G, Wandei S. Prevalence and Risk Factors Associated with Preterm Delivery among Postnatal Women in Selected Public Hospitals in Western Region of Kenya. Kenyan Journal of Nursing \& Midwifery. 2021;6(1):10-22.

29. Wagura P, Wasunna A, Laving A, Wamalwa D, Ng'ang'a P. Prevalence and factors associated with preterm birth at kenyatta national hospital. BMC Pregnancy and Childbirth. 2018;18(1):107.

30. Lynch CD, Zhang J. The research implications of the selection of a gestational age estimation method. Paediatric and perinatal epidemiology. 2007;21:8696.

31. Hamilton BE, Martin JA, Ventura SJ. Births: Preliminary data for 2007. National vital statistics reports. 2009;57(12):1-23.

\section{Figures}

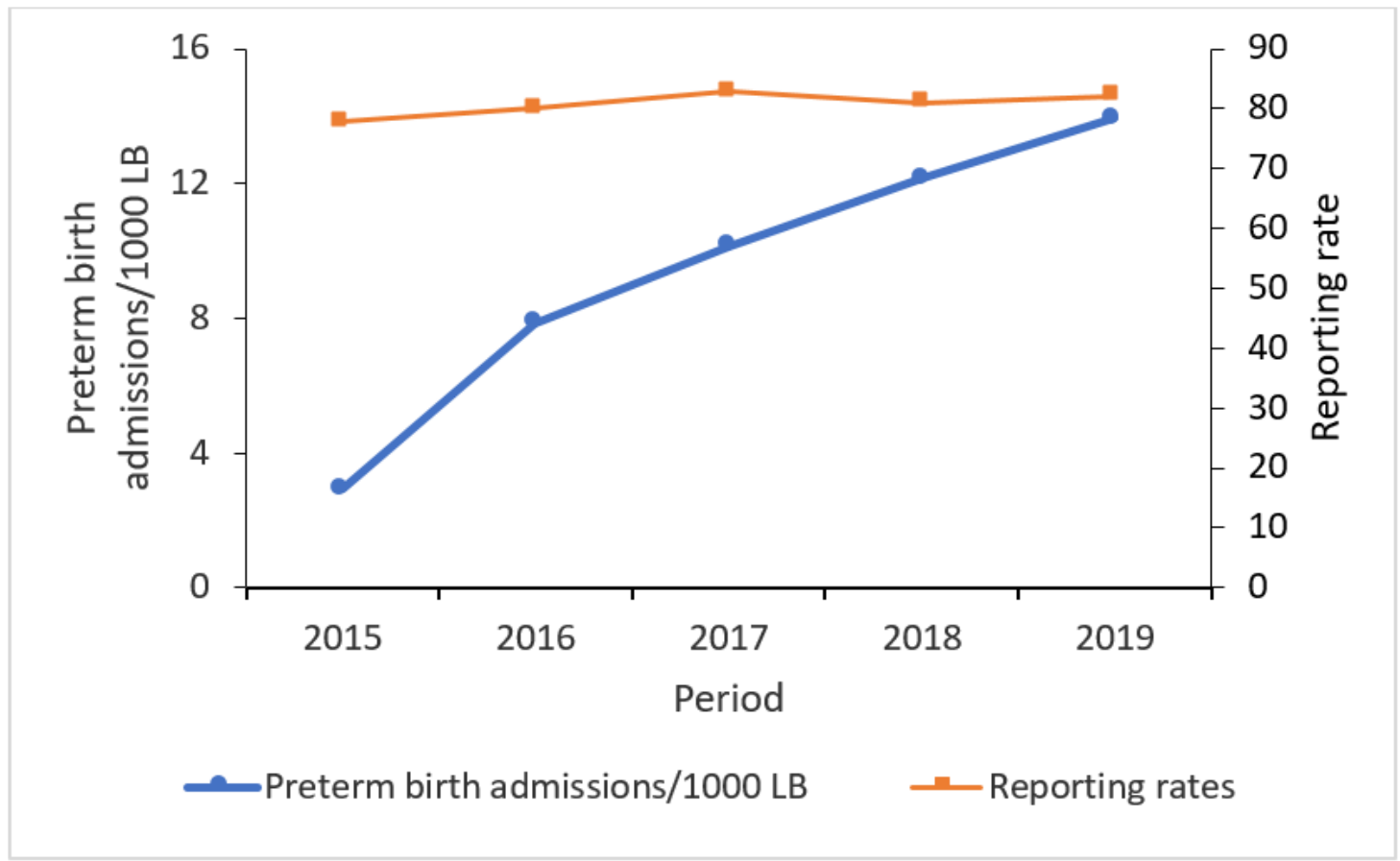

Page 6/8 
Figure 1

Annual incidence of preterm births admissions/1,000 live births, Uganda, 2015-2019

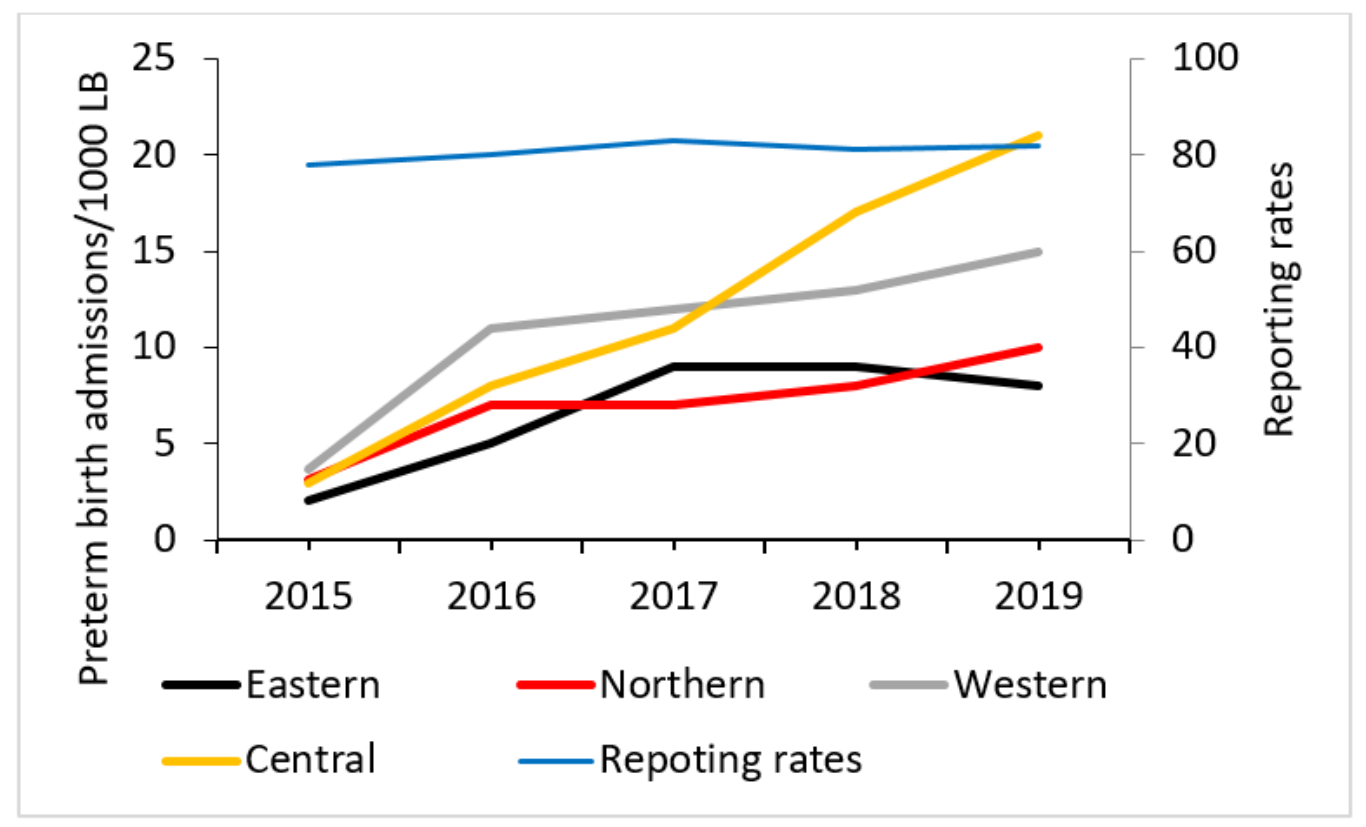

Figure 2

Trend of annual preterm births admissions /1,000 live births, regional level Uganda, 2015-2019 


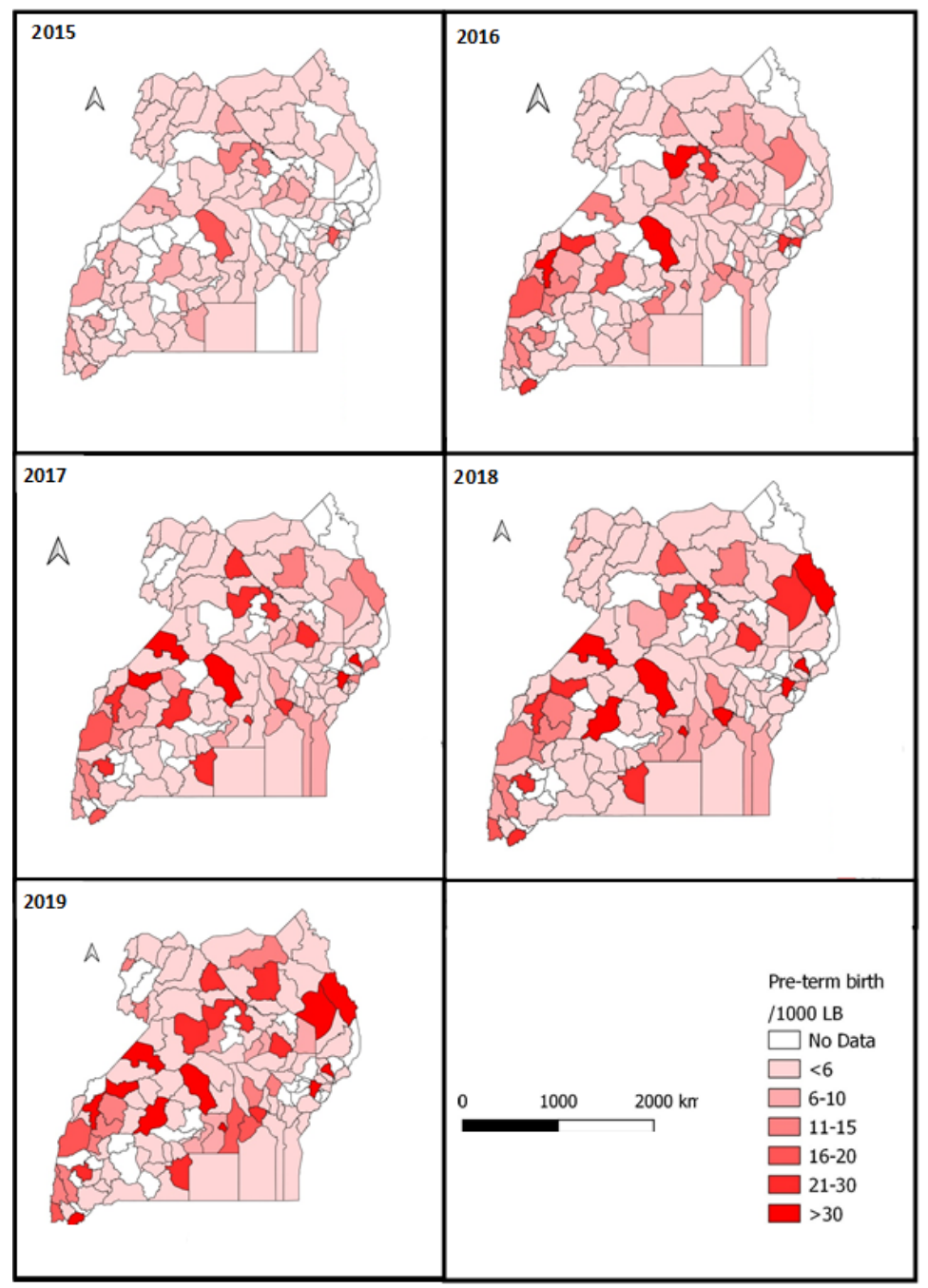

Figure 3

Spatial distribution of preterm births admissions/1,000 live births, Uganda, 2015 to 2019 